\title{
Effects of Repeatedly Heated Palm Oil on Serum Lipid Profile, Lipid Peroxidation and Homocysteine Levels in a Post-Menopausal Rat Model
}

\author{
Siti Khadijah Adam, Ima Nirwana Soelaiman, Nor Aini Umar, Norhayati \\ Mokhtar, Norazlina Mohamed, Kamsiah Jaarin*
}

\begin{abstract}
Oxidized unsaturated fatty acids may contribute to the pathogenesis of atherosclerosis. In the present study, we examined the effects of heated palm oil mixed with $2 \%$ cholesterol diet on serum lipid profile, homocysteine and thiobarbituric acid reactive substances (TBARS) levels in estrogen-deficient rats. Twenty-four female Sprague Dawley rats were ovariectomized and then were divided equally into four groups. The control group was given $2 \%$ cholesterol diet only throughout the study period. The three treatment groups received $2 \%$ cholesterol diet fortified with fresh, once-heated or five-times-heated palm oil, respectively. Serum TBARS, lipid profile and homocysteine levels were measured prior to ovariectomy and at the end of four months of the study. Five-times-heated palm oil caused a significant increase in TBARS and total cholesterol (TC) compared to control $(F=22.529, p$ $<\mathbf{0 . 0 5}$ ). There was a significant increase in serum homocysteine in the control as well as fivetimes heated palm oil group compared to fresh and once-heated palm oil groups $(F=4.432$, $p<0.05$ ). The findings suggest that repeatedly heated palm oil increase lipid peroxidation and TC. Ovariectomy increases the development of atherosclerosis as seen in this study. Feeding with fresh and once-heated palm oil does not cause any deleterious effect but repeatedly heated oil may be harmful because it causes oxidative damage thereby predisposing to atherosclerosis.

KEYWORDS: palm oil, heated oil, menopause, atherosclerosis, lipid peroxidation
\end{abstract}

\section{INTRODUCTION}

Atherosclerosis is one of the leading causes of death in the developed countries. It is a slow but progressive disease, which may begin in childhood with the development of fatty streaks. The incidence of atherosclerosis and cardiovascular disease in women is lower compared to men of similar age (1). However, the incidence of atherosclerosis in women increases after

*To whom correspondence should be addressed:

Professor Kamsiah Jaarin M. D., M. Sc.

Department of Pharmacology

Faculty of Medicine, Universiti Kebangsaan Malaysia

Jalan Raja Muda Abdul Aziz

50300 Kuala Lumpur, MALAYSIA.

Tel: 603-92897281/7285

Fax: 603-26938205

E-mail: kamsiah@medic.ukm.my menopause due to a decrease in estrogen, a hormone thought to have cardioprotective effects during the premenopausal period (2). Estrogen therapy was shown to reduce low-density lipoprotein (LDL) levels and increase high-density lipoprotein (HDL) levels in postmenopausal women (3). Estrogen also has antioxidant properties $(4,5)$ which is protective against lipid peroxidation. Atherosclerotic lesions in humans and animals appear to be related to elevated plasma total cholesterol (TC), LDL and decreased HDL. The exact mechanisms explaining how hypercholesterolemia can cause atherosclerosis are still unclear. Lipid deposition on the arterial wall likely starts with the movement of LDL from the blood into the vessel wall. LDL is oxidized becoming particularly atherogenic (6). Oxidized LDL (oLDL) may directly alter both the structure and the function of the endothelial cells. 
Consequently, oLDL also may chemotactically attract monocytes and macrophages to the endothelium which then develop into the lipid laden foam cells of an atheromatous plaque (7). oLDL is also more avidly taken up by macrophages via their scavenger receptors than unoxidized LDL (8).

Homocysteine is known as an independent risk factor of atherosclerosis (9). Homocysteine promotes atherosclerosis by a variety of mechanisms (10). In addition to directly damaging blood vessels, altered metabolism of homocysteine is also involved in the oxidative process occuring in atherogenesis (11).

Much of the fat consumed in our diet has been exposed to heat during processing and in the preparation of food during cooking. In deep-frying, oil is heated above $150 \mathrm{oC}$ for a long period of time. This heating process causes changes in the properties of the oil by chemical reactions of oxidation, hydrolysis and polymerization. When frying oil is heated, hydroperoxides and aldehydes are mainly formed (12) and are absorbed into the fried foods. Thus, these products enter systemic circulation. Malondialdehyde (MDA) is usually measured as a marker for lipid peroxidation level. Thibarbituric acid (TBA) assay is the most common method to be used to measure MDA. However, it is more appropriate to express the results as thiobarbituric acid reactive substances (TBARS) rather than MDA because other products may also form during the assay (13).

The common practice of repeatedly using the oil for frying may generate free radicals that are harmful to our health. Such practice appears to cut the cost of cooking without considering its effects on health. Several studies had demonstrated the adverse effects of oxidized dietary fats on human and experimental animals. Owu DU et al (14) and Izaki Y et al (15) reported that consumption of oxidized oil caused liver dysfunction. Acceleration of fatty streak formation had been reported in rabbits fed oxidized lipid (16). Rats fed thermally oxidized oil showed an increase in plasma glucose as well as a decrease in plasma vitamin $\mathrm{E}$ and vitamin $\mathrm{A}$ in the liver (17).

In view of the potential hazardous effect of heated oils on health, this study was planned to determine the effects of thermally oxidized palm oil taken together with $2 \%$ cholesterol diet on the factors related to atherosclerosis in female rats made estrogen-deficient by ovariectomy. This gives us information on the effects of reheated palm oil on post-menopausal women in particular, and the population in general.

\section{MATERIALS AND METHODS}

\section{Experimental animals}

Twenty-four healthy and mature female Sprague-
Dawley rats (200-250g) were obtained from the Animal Unit, Universiti Kebangsaan Malaysia. The rats were housed in cages at room temperature and a 12-hour light cycle. They had access to tap water ad libitum and were administered $150 \mathrm{~g}$ of test diet/week. All procedures were reviewed and approved by the Universiti Kebangsaan Malaysia Animal Ethic Committee (UKM AEC: FAR/2003/Kamsiah/25Jan/090).

\section{Source and preparation of diets}

Palm oil (Lam Soon Edible Oil, Malaysia) used was fresh, once-heated or five-times-heated as described by Owu et al (14). Briefly, 2.5L of palm oil was used to fry $1 \mathrm{~kg}$ (approximately 25 pieces) of 'keropok lekor' (fishflavoured chips) in a metal wok at $180 \mathrm{oC}$ for 10 minutes. To prepare five-times-heated oil, the whole frying process was repeated four more times with a fresh batch of 'keropok lekor' and five hours cooling interval. No fresh oil was added between batches to replace oil absorbed by the frying material.

The test diets were formulated by mixing $15 \%(\mathrm{w} / \mathrm{w})$ of palm oil with ground $2 \%$ cholesterol diet (MP Biomedicals Inc, Australia). The pellets were reformed and dried in an oven at $80 \mathrm{oC}$ overnight.

\section{Study design}

The rats $(n=24)$ were allowed to acclimatize for 1 week prior to treatment and were ovariectomized ahead of the study. They were randomly divided equally into four groups; with six rats per group. Group I was fed with $2 \%$ cholesterol diet (control), group II, III and IV were fed with $2 \%$ cholesterol diet fortified with fresh palm oil (FPO), once-heated palm oil (1HPO) and fivetimes-heated palm oil (5HPO), respectively for four months. The mean body weight and food intake were taken weekly during the study period. The fasting (18 hours) serum for lipid profile, thiobarbituric acid reactive substances (TBARS) and homocysteine analyses was taken prior to ovariectomy and at the end of four months of study. Serum was stored at $-70 \mathrm{oC}$ for further analyses.

\section{Serum thiobarbituric acid reactive substances (TBARS)}

TBARS level in the serum was determined using a method described by Ledwozyw A et al (18) with some modifications. A value of $0.5 \mathrm{ml}$ serum was acidified with $2.5 \mathrm{ml}$ of $1.22 \mathrm{M}$ trichloroacetic acid (TCA) $/ 0.6 \mathrm{M}$ hydrochloric acid $(\mathrm{HCl})$ and left to stand at room temperature for 15 minutes. Next, $1.5 \mathrm{ml}$ of $0.67 \%$ thiobarbituric acid (TBA)/0.05M sodium hydroxide $(\mathrm{NaOH})$ was added. The samples were incubated in a $100 \mathrm{oC}$ water bath for 30 minutes. They were left to cool at room temperature before the addition of $4 \mathrm{ml}$ of $\mathrm{n}$ - 
buthanol. After thorough mixing, the mixture was centrifuged for 10 minutes at 3000rpm. The absorbency of the upper phase was read at Ex: 515 Em: 553 by using spectroflurometer (Shimadzu RF500, Japan).

The protein content in the serum was determined using a method described by Lowry et al (19) with some modifications. A value of $0.5 \mathrm{ml}$ serum was added with $5 \mathrm{ml}$ mixture of $2 \%$ sodium carbonate (Na2CO3), $2 \%$ sodium or potassium tartrate $(\mathrm{Na} / \mathrm{K}$ tartrate) and $1 \%$ copper sulphate solution (CuSO4.5H2O) with ratio $100: 1: 1$. Subsequently, they were left to stand at room temperature for 15 minutes before the addition of $0.5 \mathrm{ml}$ of diluted Folin-Ciocalteau phenol reagent. After 35 minutes, the absorbency of the sample was measured at $700 \mathrm{~nm}$ with spectrophotometer (Shimadzu UV-160A, Japan). The serum TBARS was expressed as serum TBARS/protein.

\section{Serum lipid profile}

Serum lipid profile was determined enzymatically using commercially available kits from Randox Laboratories Ltd. (United Kingdom). These tests were performed using Vitalab Selectra E (Netherlands) following the manufacturer's instructions

\section{Serum homocysteine}

Serum homocysteine was determined by Fluorescence Polarization Immunoassay (FPIA) using commercially available kits from Abbott Laboratories (USA). The test was performed using Cobas Integra (Roche Professional Diagnostics, Switzerland) following manufacturer's instructions.

\section{Statistics}

The data was presented as the mean \pm standard error of mean (SEM). Normally distributed data were analyzed using parametric tests, i.e. Student's paired ttest and analysis of variance (ANOVA) followed by Tukey hsd post-hoc test. Data which were not normally distributed were analyzed using non-parametric tests, i.e. Kruskal-Wallis, Mann-Whitney U and WilcoxonSigned Rank tests. A value of $\mathrm{p}<0.05$ was considered significant. All analysis was conducted using Statistical Product and Service Solutions (SPSS) software (Chicago, IL, USA).
Twenty-four ovariectomized rats were divided equally into four groups; control, fresh palm oil (FPO), onceheated palm oil (1HPO) and five-times-heated palm oil (5HPO). The initial weight of the rats were taken and shown in Table 1. Subsequently, all the rats were given $2 \%$ cholesterol diet. The cholesterol diet for FPO, $1 \mathrm{HPO}$ and $5 \mathrm{HPO}$ were fortified with fresh, once-heated or five-times-heated palm oil, respectively. After four months of treatment, their average food intake was calculated. There was no significance difference in food intake among the oil-fed groups. However, the treatment groups showed a lower food intake compared to the control. Their weight gain also was calculated by deducting the weight at the end of the study with their respective initial weight. There was a significant increase in body weight at the end of the study for all groups $(\mathrm{p}<0.05)$. The highest body weight increase was observed in 5 HPO group.

Their fasting serum was taken prior to treatment and at the end of four months of study to analyse the thiobarbituric acid reactive substance (TBARS) level, lipid profile and homocysteine level. The results are expressed as percentage based on baseline values. All groups showed an increase in TBARS but the percentage increase was higher in $1 \mathrm{HPO}$ and $5 \mathrm{HPO}$ compared to control and FPO (Figure 1). There was no significance difference between $1 \mathrm{HPO}$ and $5 \mathrm{HPO}$.

For lipid profile; total cholesterol (TC), low-density lipoprotein (LDL), triglyceride and high-density lipoprotein (HDL) were measured. Similar to TBARS, there was an increasing trend in serum $\mathrm{TC}$ in the treatment groups (Figure 2). The percentage increase was significantly higher in 5HPO compared to control. Both LDL and triglyceride showed no significant difference amongst the groups (Figure 3 and 4). On the other hand, there was reduction of HDL at the end of the study in all groups (Figure 5). However, there was no significant difference in the percentage of reduction among the groups even though there was a trend seen in the figure.

The homocysteine level increased at the end of the study (Figure 6). The percentage increase in 5HPO as well as control which received only $2 \%$ cholesterol diet throughout the study period were significant compared to FPO and 1HPO.

\section{RESULTS}

\section{DISCUSSION}

Table 1: Food intake and body weight gain of rats fed respective diets after months.

Results are mean \pm S.E.M (n=6). Different superscript letters are significant based on dietary treatment $(\mathrm{p}<0.05)$

\begin{tabular}{|l|c|c|c|c|}
\hline Group & Food intake (g/week) & Initial body weight $(\mathrm{g})$ & Final body weight (g) & Body weight gain after 4 months (g) \\
\hline Control & $109.83 \pm 3.55^{\mathrm{a}}$ & 211.17 & 324.67 & $113.50 \pm 14.79 \mathrm{a}$ \\
\hline FPO & $84.83 \pm 0.70^{\mathrm{b}}$ & 209.17 & 333.50 & $124.33 \pm 22.62 \mathrm{a}$ \\
\hline 1 HPO & $83.17 \pm 1.01^{\mathrm{b}}$ & 213.50 & 334.33 & $120.83 \pm 23.38^{\mathrm{a}}$ \\
\hline 5 HPO & $83.83 \pm 2.80^{\mathrm{b}}$ & 211.17 & 339.17 & $128.00 \pm 26.21 \mathrm{~b}$ \\
\hline
\end{tabular}




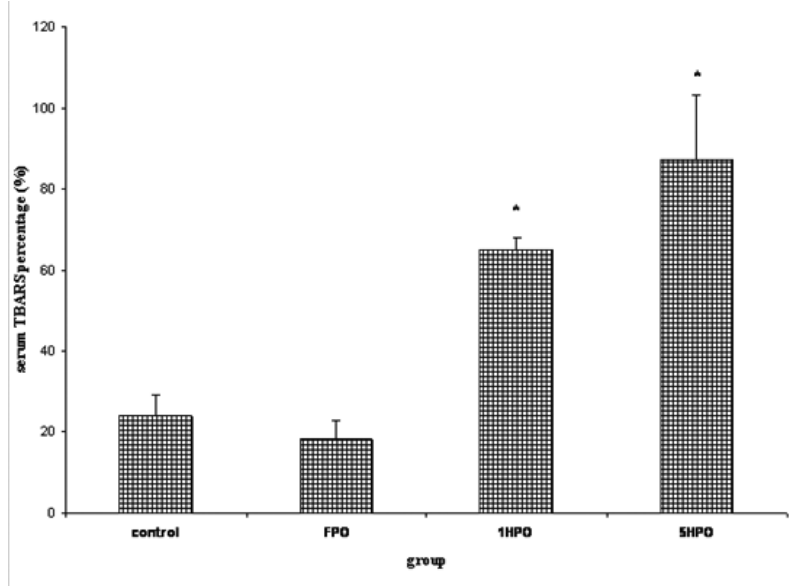

Figure 1: Percentage changes in serum TBARS with fresh and heated palm oil after four months of feeding.

Error bars represent the S.E.M.

* significant compared to control and FPO.

TBARS, thiobarbituric acid reactive substances; FPO, fresh palm oil treated group; $1 \mathrm{HPO}$, once-heated palm oil treated group; $5 \mathrm{HPO}$, fivetimes-heated palm oil treated group.

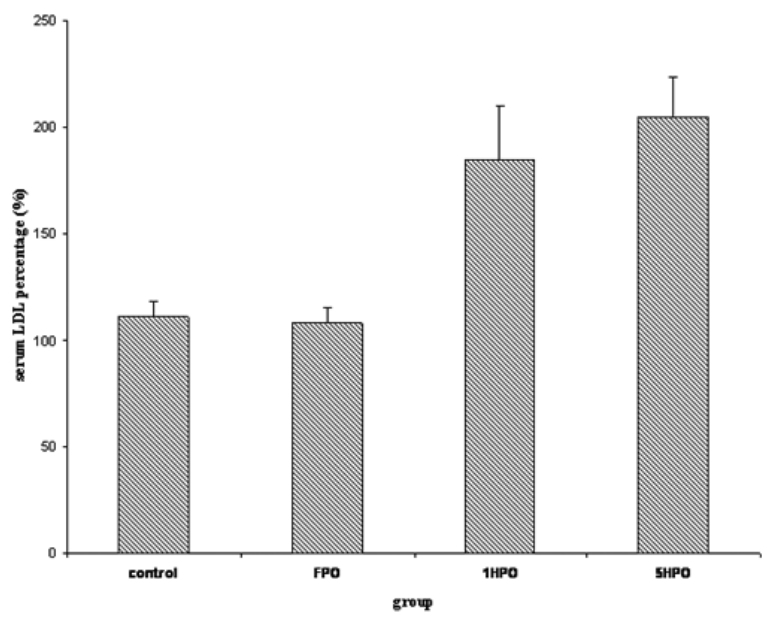

Figure 3: Percentage changes in serum LDL with fresh and heated palm oil after four months of feeding. Error bars represent the S.E.M. LDL, low-density lipoprotein; FPO, fresh palm oil treated group; $1 \mathrm{HPO}$, once-heated palm oil treated group; 5HPO, five-times-heated palm oil treated group.

This study was conducted in post-menopausal rat model to ascertain the effects of repeatedly heated palm oil on factors related to cardiovascular disease, particularly lipid peroxidation, lipid profile and homocysteine level in menopausal subject. We postulated that thermally oxidized palm oil which generates free radicals, enhances the oxidative stress secondary to estrogen deficiency and high cholesterol diet. These parameters have been attributed to atherosclerosis (20). We used $2 \%$ cholesterol diet to intensify the oxidative stress to the post-menopausal rat model. Moreover, our previous study has shown that

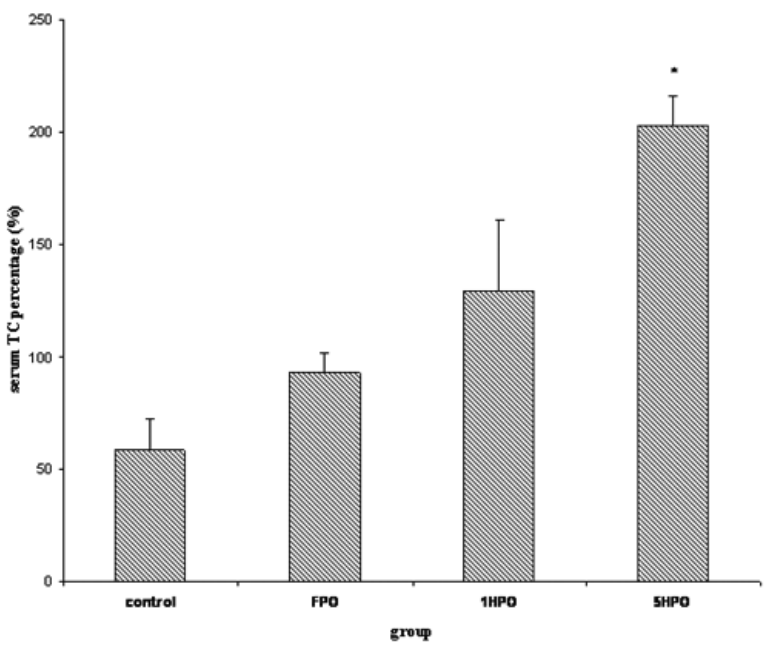

Figure 2: Percentage changes in serum TC with fresh and heated palm oil after four months of feeding. Error bars represent the S.E.M. * significant compared to control.

TC, total cholesterol; FPO, fresh palm oil treated group; $1 \mathrm{HPO}$, onceheated palm oil treated group; $5 \mathrm{HPO}$, five-times-heated palm oil treated group.

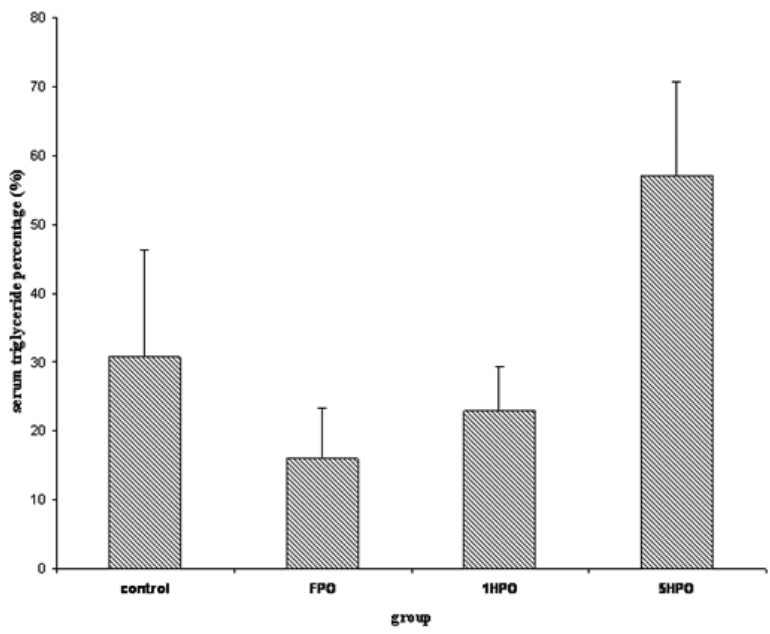

Figure 4: Percentage changes in serum triglyceride with fresh and heated palm oil after four months of feeding. Error bars represent the S.E.M.

FPO, fresh palm oil treated group; $1 \mathrm{HPO}$, once-heated palm oil treated group; 5HPO, five-times-heated palm oil treated group.

$2 \%$ cholesterol diet was atherogenic in rabbits (21). Palm oil was chosen in this study because it is widely used in Malaysia as cooking oil. The oil is often used repeatedly for deep frying in many food outlets in order to lower costs.

The heating process which causes physical changes in the oil did not have any significant effects on the food intake. This was proven by similar food intake in all the treatment groups and was associated with similar increase in their body weight, except 5HPO which observed higher increase in body weight gain compared to other groups. The reason for this is not well 


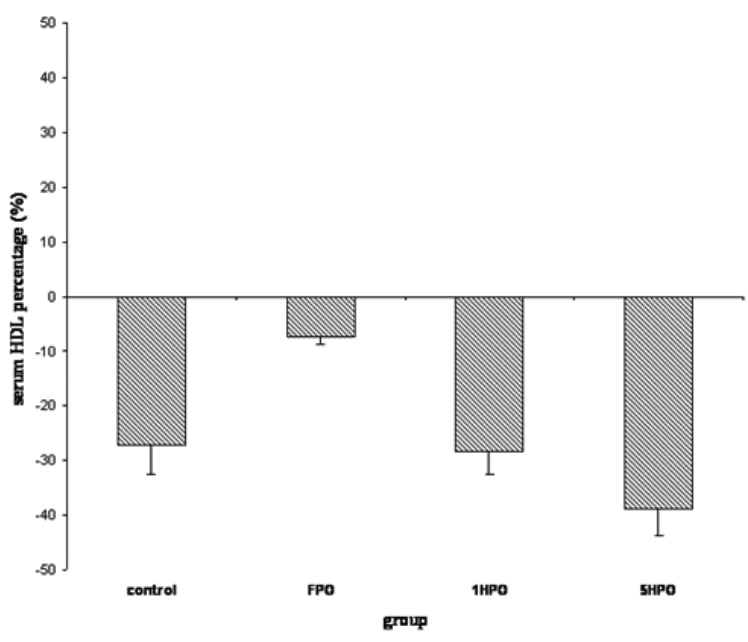

Figure 5: Percentage changes in serum HDL with fresh and heated palm oil after four months of feeding. Error bars represent the S.E.M. HDL, high-density lipoprotein; FPO, fresh palm oil treated group; 1HPO, once-heated palm oil treated group; 5HPO, five-times-heated palm oil treated group.

understood.

This present study showed that once-heated and fivetimes-heated palm oil increased lipid peroxidation as indicated by a significant increase in serum TBARS in these groups compared to control and FPO. It thus appears that percentage of rise in serum TBARS was higher in 5HPO group compared to 1HPO. However, the difference was not significant. This may suggest that repeated heating might not affect free radical formation. This finding was contrary to our expectations, as we expected repeated heating to generate more free radicals, as reported by Nwanguma et al (22). The percentage changes in TBARS in 5HPO group might attain a significant level if the period of study was prolonged. The effects of heated palm oil on serum TBARS in this study was not comparable to the finding of Benedetti et al who also reported that oxidized corn oil affect neither plasma nor liver MDA levels (17). Izaki et al also found that serum and kidney TBA-RS level were unchanged in the rats fed with thermally oxidized rapeseed oil (15). The reason for the discrepancies in the result might be due to the different types of oil: indeed, they had used unsaturated oil while we used palm oil which contains at least 50\% saturated fats (23). There is a possibility that estrogen deficiency in our study might contribute to the significant increase in serum TBARS level. In previous study by Hageman et al (24), feeding rats with heated oils also did not cause an increase in hepatic and renal microsomal fractions TBARS. We assume that the incorporation of those oils at a level of only $10 \%$ in the diet, followed by shorter duration of the study might be the contributing factors to these findings.

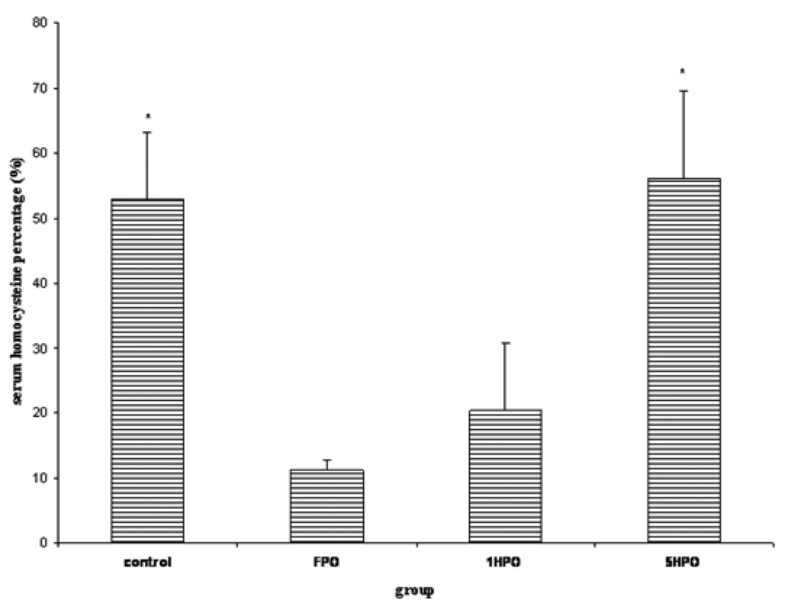

Figure 6: Percentage changes in serum homocysteine with fresh and heated palm oil after four months of feeding. Error bars represent the S.E.M.

* significant compared to FPO and $1 \mathrm{HPO}$.

FPO, fresh palm oil treated group; 1HPO, once-heated palm oil treated group; 5HPO, five-times-heated palm oil treated group.

There was an increasing trend in serum TC in all oilfed groups. The percentage increase in TC was only significant in 5HPO group compared to control. The increase in serum TC in the study groups is probably secondary to $2 \%$ cholesterol diet intake. Feeding with repeatedly heated palm oil appears to accelerate the increase in serum TC in this group. The effect of heating on TC in this present study was not in agreement with Hur et al who reported that heated corn oil reduced plasma cholesterol in rabbits (25). The type of animal, the oil used and the ovariectomy procedure might be the contributing factors.

In this study we found that there was a significant increase in serum homocysteine level in the control as well as 5HPO. There were no significant changes in serum homocysteine in FPO and 1HPO groups. The increase in serum homocysteine level in the control might be due to estrogen deficiency as a result of ovariectomy. Feeding with either fresh or once-heated palm oil appears to offer some protective effects. The protective effects against the rise in serum homocysteine by palm oil reduced while heating the oil, repeatedly. The loss in the protective effects of palm oil could be attributed to destruction of the heat labile vitamin such as tocotrienol (26).

There was an increasing trend in serum LDL, TG and decreasing trend in HDL cholesterol in all the groups. However, the changes were not significant. The changes in LDL cholesterol in this study were not comparable to our earlier work in which we found that fresh and heated palm oil increase LDL level (27). The duration of feeding which is shorter (4 months) in the present study and $2 \%$ cholesterol diet might responsible for the 
differences in the results.

The changes in serum TG level in this study are similar to those reported by Staprans et al who found that there was no difference in serum TG concentrations between control and oxidized-diet group (16). On the other hand, it was contradictory to the findings of Rueda-Clausen et al who reported that consumption of deep-fried palm oil increased serum TG level in humans (28). These contradictory results could be due to factors such as the oil preparation process, the subject's metabolic conditions and the duration of the study.

It was expected that high cholesterol diet increases HDL cholesterol. However, this was not observed in our study even though the animals were fed with $2 \%$ cholesterol diet throughout the study period. Instead, we found that there was a decreasing trend in $\mathrm{HDL}$ cholesterol in all the groups. The decreasing trend in HDL cholesterol might be due to estrogen deficiency. Repeatedly heated palm oil did not interfere with changes in HDL cholesterol.

A limitation of this study is the small sample used; further, larger studies are appropriate. Our previous study (29) had used soy oil, which contains higher level of polyunsaturated fatty acids (PUFA) compared to palm oil (23) showed some appealing results. Interestingly, the TBARS level of the group fed with repeatedly heated soy oil was higher compared to other treatment groups. This proves that palm oil which contains high amount of monounsaturated fatty acids (MUFA) is less susceptible to oxidation compared to soy oil $(30,31)$. In earlier studies, we had found that consumption of repeatedly heated palm and soy oils caused adverse effects on bone histomorphometry ovariectomy-induced rats (32). Moreover, the study also showed that soy oil had further deteriorated the bone changes compared to palm oil. From these results, it was obvious that repeatedly heated oils, especially soy oil may contribute to the pathogenesis of atherosclerosis and osteoporosis in post-menopausal woman, particularly.

In conclusion, repeatedly heated palm oil appears to increase lipid peroxidation and cholesterol level in a post-menopausal rat model. Ovariectomy increases serum homocysteine level and feeding with either fresh or once-heated palm oil offers some protection which is lost when the oil was repeatedly heated. Further studies are acquired to ascertain whether the increase in these parameters has detrimental effects on blood vessels and is a potential danger for cardiovascular disease in menopausal subject.

\section{ACKNOWLEDGMENTS}

This study was funded by grant IRPA 06-02-02-0050EA242. The authors wish to thank Puan Azizah
Othman, Puan Sinar Suriya Muhamad as well as other staffs in Chemical Pathology Laboratory, HUKM for valuable assistance.

\section{REFERENCES}

1. Rossouw JE. Hormones, genetic factors and gender differences in cardiovascular disease. Cardiovasc Res. 2002; 53(3): 550557.

2. Baker L, Meldrum KK, Wang M, et al. The role of estrogen in cardiovascular disease. J Surg Res. 2003; 115(2): 325-344.

3. Nabulsi AA, Folsom AR, White A, et al. Association of hormone-replacement therapy with various cardiovascular risk factors in postmenopausal women. The Atherosclerosis Risk in Communities Study Investigators. N Eng J Med. 1993; 328(15): 1069-1075.

4. Ayres S, Tang M, Ravi Subbiah MT. Estradiol-17 $\beta$ as an antioxidant: some distinct features when compared with common fat-soluble antioxidants. J Lab Clin Med. 1996; 128(4): 367-375.

5. Badeau M, Adlercreutz H, Kaihovaara P, Tikkanen MJ. Estrogen A-ring structure and antioxidative effect on lipoproteins. J Steroid Biochem Mol Biol. 2005; 96(3-4): 271-278.

6. Osterud B, Bjorklid E. Role of monocytes in atherogenesis. Physiol Rev. 2003; 83(4): 1069-1112.

7. Plutzky J, Libby P. Pathophysiology of atherosclerotic heart disease. In: Tonkin AM, editor. Atherosclerosis and heart disease. London, UK: Martin Dunitz; 2003. p. 1-12.

8. Steinberg D, Witztum JL. Lipoproteins and atherogenesis. Current concepts. JAMA. 1990; 264(23): 3047-3052.

9. Su SJ, Huang LW, Pai LS, Liu HW, Chang KL. Homocysteine at pathophysiologic concentrations activates human monocyte and induces cytokine expression and inhibits macrophage migration inhibitory factor expression. Nutrition 2005; 21(10): 994-1002.

10. Welch GN, Loscalzo J. Homocysteine and atherothrombosis. N Engl J Med. 1998; 338(15): 1042-1050

11. Olszewski AJ, McCully KS. Homocysteine metabolism and the oxidative modification of proteins and lipids. Free Radic Biol Med. 1993; 14(6): 683-693.

12. Dobarganes C, Márquez-Ruiz G. Oxidized fats in foods. Curr Opin Clin Nutr Metab Care 2003; 6(2): 157-163.

13. Esterbauer H, Schaur RJ, Zollner H. Chemistry and biochemistry of 4-hydroxynonenal, malonaldehyde and related aldehydes. Free Radic Biol Med. 1991; 11(1): 81-128.

14. Owu DU, Osim EE, Ebong PE. Serum liver enzymes profile of Wistar rats following chronic consumption of fresh or oxidized palm oil diets. Acta Trop. 1998; 69(1): 65-73.

15. Izaki $\mathrm{Y}$, Yoshikawa $\mathrm{S}$, Uchiyama $\mathrm{M}$. Effect of ingestion thermally oxidized frying oil on peroxidative criteria in rats. Lipids 1984; 19(5): 324-331.

16. Staprans I, Rapp JH, Pan XM, Hardman DA, Feingold KR. Oxidized lipids in the diet accelerate the development of fatty streaks in cholesterol-fed rabbits. Arterioscl Throm Vasc Biol. 1996; 16(4): 533-538.

17. Benedetti PC, D'Aquino M, Di Felice M, Gentili V, Tagliamonte B, Tomassi G. Effects of a fraction of thermally oxidized soy bean oil on growing rats. Nutr Rep Int. 1987; 36(2): 387-401.

18. Ledwozyw A, Michalak J, Stepien A, Kadziolka A. The relationship between plasma triglycerides, cholesterol, total lipids and lipid peroxidation products during human atherosclerosis. Clin Chim Acta 1986; 155(3): 275-283.

19. Lowry OH, Rosebrugh NJ, Farr AL, Randall RJ. Protein measurement with the Folin phenol reagent. J Biol Chem. 1951; 193(1): 265-75. 
20. Maxwell SRJ, Lip GYH. Free radicals and antioxidants in cardiovascular disease. Br J Clin Pharmacol 1997; 44(4): $307-$ 317.

21. Kamsiah J, Nafeeza MI, Ngang AC. Suppression of atherogenesis in cholesterol-fed rabbits treated with nicardipine. Asia Pac J Pharm. 1994; 9(3): 183-187.

22. Nwanguma BC, Achebe AC, Ezeanyika LUS, Eze LC. Toxicity of oxidized fats II: tissue levels of lipid peroxides in rats fed a thermally oxidized corn oil diet. Food Chem Toxicol. 1999; 37(4): 413-416.

23. Cottrell RC. Introduction: nutritional aspects of palm oil. Am J Clin Nutr. 1991; 53(4 Suppl): 989S-1009S.

24. Hageman G, Verhagen H, Schutte B, Kleinjans J. Biological effects of short-term feeding to rats of repeatedly used deepfrying fats in relation to fat mutagen content. Food Chem Toxicol. 1991; 29(10): 689-698.

25. Hur SJ, Du M, Nam K, Williamson M, Ahn DU. Effect of dietary fats on blood cholesterol and lipid and the development of atherosclerosis in rabbits. Nutr Res. 2005; 25(10): 925-935.

26. Adam SK, Sulaiman NA, Md Top AG, Jaarin K. Heating reduces vitamin $\mathrm{E}$ content in palm and soy oils. Malays $\mathrm{J}$ Biochem Molec Biol. 2007; 15(2): 76-79.

27. Kamsiah J, Norhayati M, Norzana G, Nor Aini U, Ima-Nirwana S. Effects of heated vegetable oils on serum lipids and aorta of ovariectomized rats. Pak J Nutr. 2006; 5(1): 19-29.

28. Rueda-Clausen CF, Silva FA, Lindarte MA, et al. Olive, soybean and palm oils intake have a similar acute detrimental effect over the endotelial function in healthy young subjects. Nutr Metab Cardiovas Dis. 2007; 17(1): 50-57.

29. Adam SK, Das S, Soelaiman IN, Umar NA, Jaarin K. Consumption of repeatedly heated soy oil increases the serum parameters related to atherosclerosis in ovariectomised rats. Tohoku J Exp Med. 2008; 215(3): 219-226.

30. Witztum JL, Steinberg D. Role of oxidized low density lipoprotein in atherogenesis. J Clin Invest. 1991; 88(6): 17851792.

31. Lapointe A, Couillard C, Lemieux S. Effects of dietary factors on oxidation of low-density lipoprotein particles. J Nutr Biochem. 2006; 17(10): 645-658.

32. Shuid AN, Chuan LH, Mohamed N, Jaarin K, Fong YS,

Siti Khadijah Adam is currently a PhD student at Universiti Kebangsaan Malaysia. She received a BSc (Hons) in Biomedical Science from Universiti Malaya. She is doing research in cardiovascular pharmacology under the Department of Pharmacology and expected to graduate in 2009.

Ima Nirwana Soelaiman (MBBS, PhD) is a Professor and Head of the Department of Pharmacology, Faculty of Medicine, Universiti Kebangsaan Malaysia. She is conducting research in bone metabolism.

Nor Aini Umar (MD, DCP Pathology) is a Senior Lecturer at Department of Pathology, Faculty of Medicine, Universiti Kebangsaan Malaysia.

Norhayati Moktar (MD, PhD) is a Professor at Department of Parasitology, Faculty of Medicine, Universiti Kebangsaan Malaysia.

Norazlina Mohamed (BSc, PhD) is a Senior Lecturer at Department of Pharmacology, Faculty of Medicine, Universiti Kebangsaan Malaysia. She is conducting research in bone metabolism.

Kamsiah Jaarin (MD, MSc) is a Professor at Department of Pharmacology, Faculty of Medicine, Universiti Kebangsaan Malaysia. She is conducting research in cardiovascular pharmacology. 